\title{
Investigation the Influence of SPIF Parameters on Residual Stresses for Angular Surfaces Based on Iso-Planar Tool Path
}

\author{
Mustafa Mohammed Abdulrazaq * Safaa Kadhum Gazi** \\ Marwa Qasim Ibraheem*** \\ *** Department of Production Engineering and Metallurgy / University of Technology \\ *Email: mustafaalneame@yahoo.com \\ **Email: Safaa_kadhim1988@yahoo.com \\ ***Email: techmarwa888@yahoo.com
}

(Received 5 June 2018; accepted 18 September 2018)

https://doi.org/10.22153/kej.2019.09.002

\begin{abstract}
Incremental Sheet Metal Forming (ISMF) is a modern sheet metal forming technology which offers the possibility of manufacturing 3D complex parts of thin sheet metals using the CNC milling machine. The surface quality is a very important aspect in any manufacturing process. Therefore, this study focuses on the resultant residual stresses by forming parameters, namely; (tool shape, step over, feed rate, and slope angle) using Taguchi method for the products formed by single point incremental forming process (SPIF). For evaluating the surface quality, practical experiments to produce pyramid like shape have been implemented on aluminum sheets (AA1050) for thickness (0.9) mm. Three types of tool shape used in this work, the spherical tool gave higher residual stresses than other types, also three levels for each of step over and feed rates utilized. It found that residual stresses was raised up with increasing the step over and feed rate values, the effect of these variables studied on two slope angles. By using analysis of variance method (ANOVA) found that the most influential parameter is step over with $(59.18 \%)$ and $(65.42 \%)$ for both slop angles; $\left(\alpha=45^{\circ}\right)$ and $\left(\alpha=55^{\circ}\right)$ respectively.
\end{abstract}

Keywords: Incremental Sheet Metal Forming, Residual stresses, Taguchi, single point incremental forming.

\section{Introduction}

Incremental sheets metal forming is a high flexible forming process, which can forming the sheets through the motion of non-traditional tool to manufacture the complicated products shapes, and the equipments of forming is appropriate for a wide variant products without expensive investments or matched tools through the movement of the tools onto certain tool path [1, 2]. The small plastic deformation zone that occur in the incremental sheet forming mechanism produced higher strains compared to conventional forming operations and it required low forces to implement the forming process [3]. So a different and complex 3D shapes can be produced through the tool movement along accurate designed paths, so there are no needs for manufacturing special tool [3].

Single point incremental forming (SPIF) is a comparative sheets forming technique that allow forming of complex shape without a specific die using single point tools 3 -axis $\mathrm{CNC}$ milling machine [4]. The technology of (SPIF) uses layer manufacturing concepts. It implements the part geometry details in to a group of parameters by $2 \mathrm{D}$ layers, and later the local plastic deformations are occurred layer-by-layer using the motion of computer numerical control of a simple forming tools to manufacture products which have complicated shapes as shown in figure (1) $[5,6]$. 


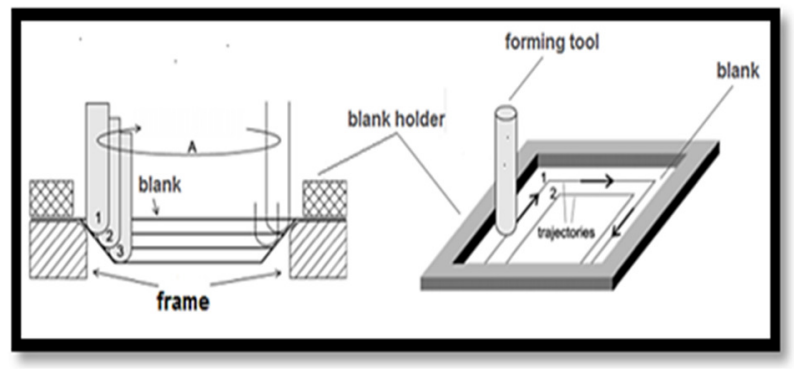

Fig. 1. Schematic representation of the SPIF process

In 2013 Radu Crinaa, et al. [7]: Investigated the residual stresses distribution through parts produced by single point incremental forming (SPIF) made by AA1050 pure aluminum. Operation variables were variants to find out their effect on residual stress values and distributions: diameter of tool (d), tool vertical step $(\Delta \mathrm{z})$, and spindle speed $(\omega)$. He found that increasing the tool diameter decreasing the residual stresses, contrariwise with using large values of spindle speed and vertical step which gave high amounts of residual stresses.

Bogdan Chirita, et al. (2014) [8]: studied the distribution of residual stresses through the part formed by (SPIF) operation as a work parameters function and to find out its influence on part quality using the same parameters above, it was found a favorable residual stress state and implying a suitable quality of the samples could be given using low diameter of the tool and step size as well, with higher values of spindle speed.

This study focuses on the resultant residual stresses by forming variables, namely; (tool shape, step over, feed rates, and slope angle) using Taguchi method for the samples formed by (SPIF) single point incremental forming method.

G. Vigneshwaran et al. (2015) [9], implemented an optimization task by discovering the influence of operation variables such as tool diameter, step size, spindle speeds and feed rates on the wall angle. Aluminum sheets (Al 6063- O) with $1 \mathrm{~mm}$ thickness has been used as a sheet metal. An L9 (34) Taguchi orthogonal array has been used for designing the experiments and analyzing the result. Using the (ANOVA) technique, the results have been examined and it showed that the tool diameter, step size, spindle speeds and feed rates contribute $(4 \%, 57 \%, 10 \%$ and $29 \%$ ) respectively, provide a higher wall angle of $\left(55^{\circ}\right)$.

\section{Residual Stress}

Residual stress is an unavoidable concomitant with every manufacturing processes and fabrication operations and could also grows through the service, it can occurs with any sets of circumstances that lead to differential expansions or contractions among the adjacent pieces on a body in which the local yield strength is exceeded. There are two types of Residual stresses tensile and compressive that depend on locations and the non-uniform volumetric type that occurs due to localizing the stress through the forming process as in shot peening, contoure rolling, etc. [10].

The determining of precise for residual stress is difficult using analytical methods. Usually the value of residual stress is determined through experimental process. Most of these processes are destructive. So the (XRD) X-rays diffraction method is the main non-destructive techniques in residual stresses measurements. [11].

$\mathrm{X}$-ray emitted through a particular x-rays tube concentrated to a fixed pattern on the spectrometer axes (goniometer). Diffracting Xrays on samples in an overall angle of diffractions equal to $(2 \theta)$. Through a detector device the diffracting x-ray is computed. Figure (2) clarify the principles of the process for the (XRD) method.

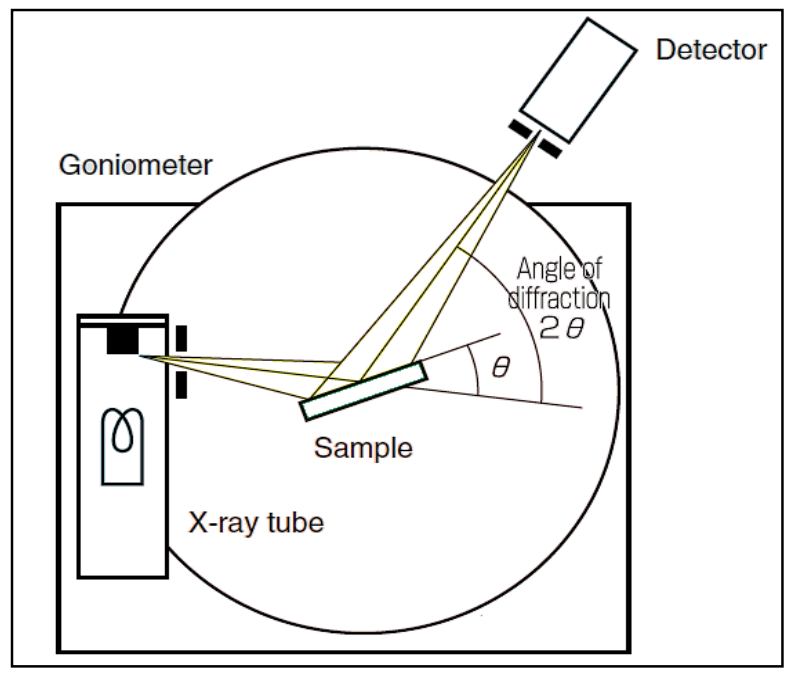

Fig. 2. Principles of (XRD) process.

Assessment of residual stresses by X-rays diffraction depends on calculating the changes of inter-planar spacing of crystal lattice. 


\section{Taguchi Experimental Design Method}

This technique depends on two groups; the first one is a special type of matrix called "orthogonal array (OA)" includes number of tests based on the number of levels for the controlling parameters, and the second one is $(\mathrm{S} / \mathrm{N})$ the signals to noise ratio. The expression 'signal' indicating to the required values (mean) of the outputs characteristics, beside that the expression (noise) indicating to the unrequired values. The calculation of $(\mathrm{S} / \mathrm{N})$ ratios is varying depending on objectives functions, i.e., a characteristics amount. [12].

Designing the method using MINITAB16 program as follow:

\section{$\mathrm{STAT} \longrightarrow \mathrm{DOE} \longrightarrow$ Taguchi $\longrightarrow$ Create Taguchi design}

\section{Variance Analysis}

The experimental work results could be investigated by (ANOVA) variance analysis to discover the effecting of forming variables on residual stresses through the entire process. In the analysis, the ratio between mean square errors and residual called $\mathrm{F}$ - ratio and it utilized for determining the importance of a parameter. $\mathrm{F}$ ratio correspondent to $95 \%$ reliable levels in calculations of the operation variables. $\mathrm{P}$ values are the report of importance levels of each parametr (appropriate and inappropriate) [13].

\section{Machines and Tools}

The experimental equipment includes: $\mathrm{CNC}$ milling machine, forming frame, sheet metal and the tools for forming.

The incremental sheet metal forming is normally implemented on CNC milling machine, where it's capable for assigning and controlling the movement of the forming tool through a certain 3D path.

The experimental work has been implemented on 3-axes CNC machine (C-tek) model (KM80D), that locates in University of Technology/ workshops and training center for carried out forming process on the samples. The specifications of milling machine clarified in Table (1)
Table 1,

The CNC milling machine Specification

\begin{tabular}{llc}
\hline Aspect & Specification & Units \\
\hline Type & (KM-80D) & \\
Travel (x, y, z) & $1500 \times 600 \times 400$ & $\mathrm{~mm}$ \\
Max. Spindle Speed & 8000 & $\mathrm{rpm}$ \\
Number of Axis & Three & \\
CNC Controller & CNT Series & \\
Other Specifications & Off Line Program. Movable \\
& Head & \\
\hline
\end{tabular}

The hollow cylindrical frame is manufactured from medium carbon steel by metric turning machine with outer diameter $(200 \mathrm{~mm})$ and inner diameter $(170 \mathrm{~mm})$ and height of $(200 \mathrm{~mm})$. A ring with radii equals to the radii of the forming frame has been used as a blank holder. As shown in Figure (3)

A piece of wood is utilized as a backing plate between the sheet metal blank and the forming frame in order to support the blank while forming and to compensate the lack of shape matching between the square top-view of the truncated pyramid product and the circular opening of both the forming frame and the blank holder. The backing plate is illustrated in figure (3)

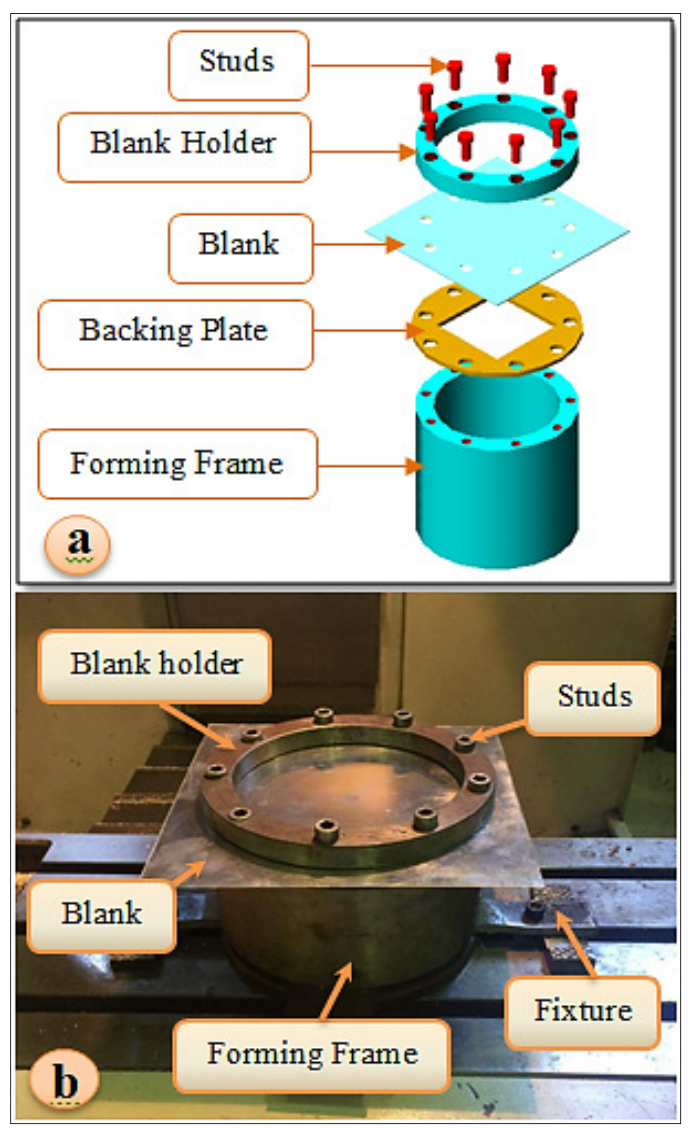

Fig. 3. Forming framework, (a) schematic illustration, (b) physical blank holder and forming frame. 
Three types of tool shapes have been utilized in this work: (spherical, hemispherical and toroidal heads) of $12 \mathrm{~mm}$ diameter for each one illustrated in Figure (4). The lengths of all these types are $(110 \mathrm{~mm})$ manufactured from tool steel materials DIN-1530 with hardness of (60 HRC).

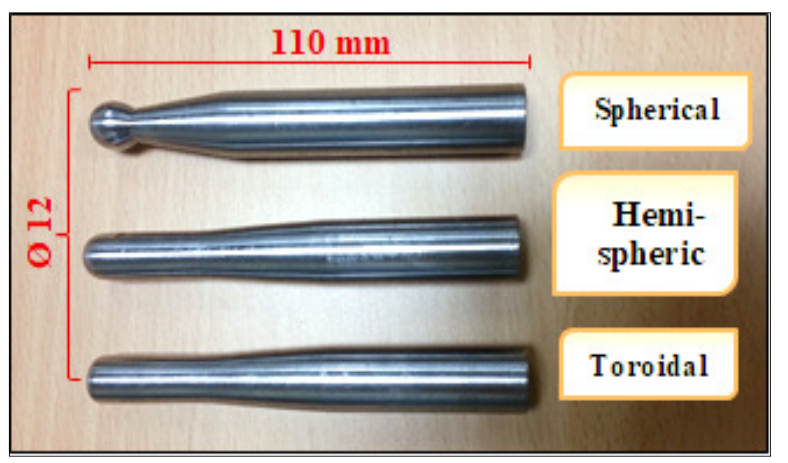

Fig. 4. The three types of forming tools.

The sheet metal material which is used in this work is Aluminum AA1050 alloy. Table (2) clarifies the chemical compositions of the sheet metal.

Table 2,

Chemical compositions of Aluminum sheets (AA 1050).

\begin{tabular}{lllll}
\hline Elements & $\mathbf{A l}$ & $\mathbf{S i}$ & $\mathbf{F e}$ & $\mathbf{C u}$ \\
\hline exp. & 99.3 & 0.096 & 0.33 & 0.035 \\
\hline $\mathbf{M n}$ & $\mathbf{M g}$ & $\mathbf{T i}$ & $\mathbf{V}$ & $\mathbf{Z n}$ \\
\hline 0.026 & 0.025 & 0.013 & 0.018 & 0.042 \\
\hline
\end{tabular}

The original dimensions of the sheets are $(250 \times 250 \times 0.9) \mathrm{mm}$, and the work area diameter is $170 \mathrm{~mm}$ according to the inner size of the blank holder as shown in Figure (5).

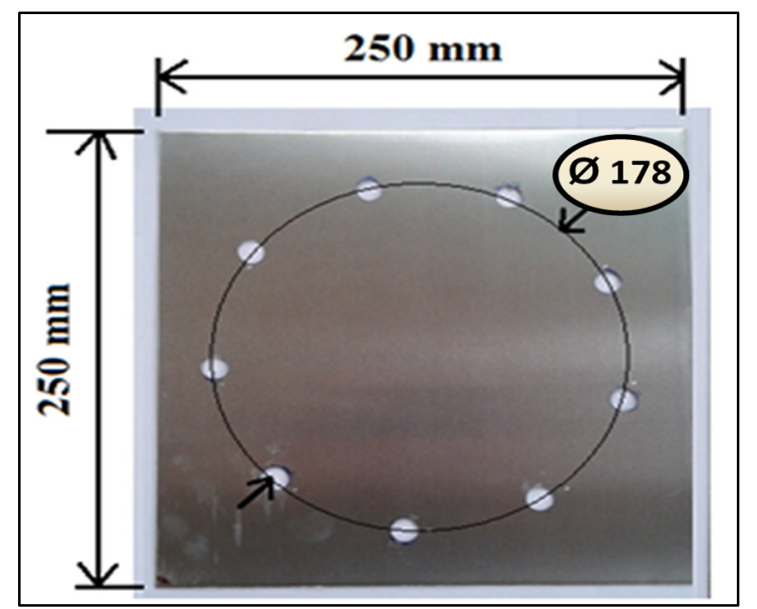

Fig. 5. Size of Aluminum blank used.
The CAD model of the products created by using Siemens (UGS-NX9) program, for applying the incremental sheet metal operation on a pyramid like shape with depth (40) $\mathrm{mm}$. Two different angles for the inclined walls $\left(45^{\circ}\right.$ and $55^{\circ}$ ), each two facing walls are equal as shown in figure (6). This geometry is kept constant for all the nine samples.

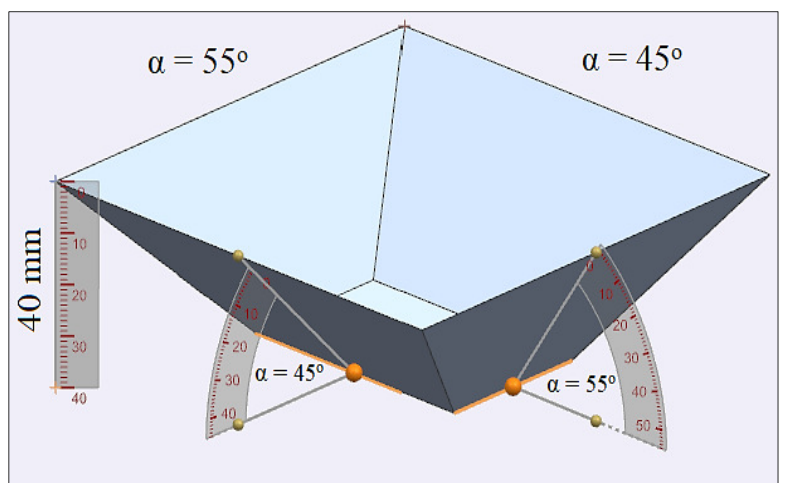

Fig. 6. Dimensions details for the CAD model of the product.

In Incremental Forming, the tool motion is controlled numerically. Consequently, a tool path of (Z-level) type with constant vertical step called "Iso-planar" tool path is generated for all products.

The tool path starts from the outside of the shape towards the inner sides and incrementally goes down in the Z-direction by a constant $(\Delta \mathrm{Z})$ value as shown in Figure (7). NC codes are obtained from the generated tool path and transferred to the CNC machine.

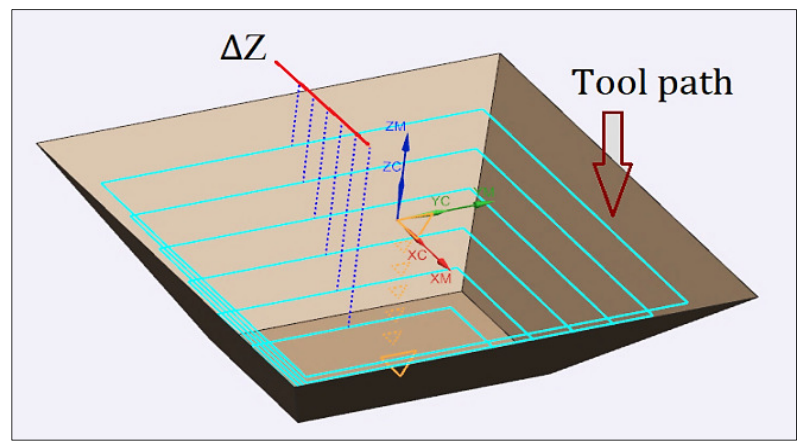

Fig. 7. Iso-planar tool path generation using UGSNX5 software.

\section{Design of Experiments}

The designing of experimental tests has a great influence on the required experimental tests 
numbers. Accordingly, the experiments of (ISMF) required an appropriate design. The overall number of experimental tests is (9) experiments, on the basis of (3) levels and (3) variables $\left(3^{3}\right)$ for partial design, the parameters levels are listed in table (3). The constant variables are:

- Tool path: Iso-planer

- Spindle speed: 1000 r.p.m

- Lubricant: paraffin based gear oil SAE 140

Table 3,

(ISMF) parameters and levels.

\begin{tabular}{lllll}
\hline No. & Parameter & Level 1 & Level 2 & Level 3 \\
\hline 1 & Tool Shape & $\begin{array}{l}\text { Hemi- } \\
\text { Spherical }\end{array}$ & Toroidal & Spherical \\
2 & $\begin{array}{l}\text { Step over } \\
(\mathrm{mm})\end{array}$ & 0.3 & 0.5 & 0.7 \\
3 & $\begin{array}{l}\text { Feed rate } \\
(\mathrm{mm} / \mathrm{min})\end{array}$ & 800 & 1000 & 1200 \\
\hline
\end{tabular}

\section{Implementation ISMF Process}

The experimental work for implementing the nine experiments that selected by designing of Taguchi have been carried out on 3-axis CNC milling machine, fig (8) clarify the nine specimens produced by (ISMF) process using the concern forming parameters on linear interpolation. This process is followed by measurement process using XRD method to clarify the effect of the parameters on the process.

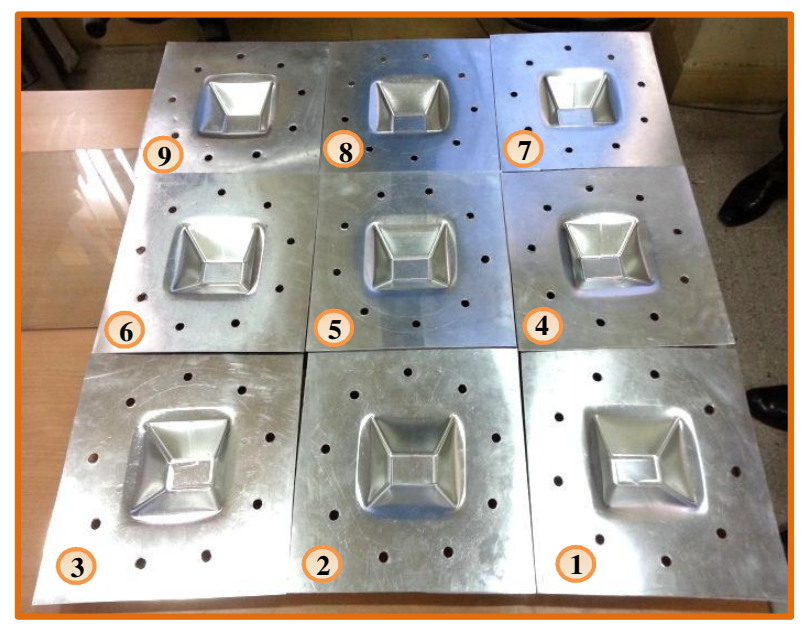

Fig. 8. Specimens after ISMF Process.

\section{Result and Discussion}

The resultant residual stresses for the samples have been measured using x-ray diffractometer of type "Shimadzu XRD-6000". This part demonstrates and discusses the results values of the tensional residual stresses depending on (3) forming variables; tool shape, feed rates and stepover, and using analysis of variance (ANOVA) technique. The results will be performed to determine the contribution percentage of these parameters in the process, and obtaining the optimum values by using Minitab program, when the experiments of the nine samples have been implemented. Table (4) clarifies these variables and the resultant residual stresses over the parts regions.

Table 4,

Experimental work readings with residual stresses

\begin{tabular}{|c|c|c|c|c|c|}
\hline \multirow[t]{2}{*}{ No. } & \multirow[t]{2}{*}{$\begin{array}{l}\text { Tool } \\
\text { Shape }\end{array}$} & \multirow{2}{*}{$\begin{array}{l}\text { Step } \\
\text { over } \\
(\mathbf{m m})\end{array}$} & \multirow{2}{*}{$\begin{array}{l}\text { Feed } \\
\text { rate } \\
\text { (mm/ } \\
\text { min) }\end{array}$} & \multicolumn{2}{|c|}{$\begin{array}{c}\text { Residual stresses } \\
\text { (Mpa) }\end{array}$} \\
\hline & & & & $\alpha=4^{\circ}$ & $\alpha=55^{\circ}$ \\
\hline 1 & Flat-end & 0.3 & 800 & 11.327 & 15.786 \\
\hline 2 & Flat-end & 0.5 & 1000 & 25.353 & 27.845 \\
\hline 3 & Flat-end & 0.7 & 1200 & 33.258 & 53.789 \\
\hline 4 & $\begin{array}{l}\text { Hemi- } \\
\text { spherical }\end{array}$ & 0.3 & 1000 & 27.902 & 21.634 \\
\hline 5 & $\begin{array}{l}\text { Hemi- } \\
\text { spherical }\end{array}$ & 0.5 & 1200 & 35.770 & 36.990 \\
\hline 6 & $\begin{array}{l}\text { Hemi- } \\
\text { spherical }\end{array}$ & 0.7 & 800 & 37.927 & 57.049 \\
\hline 1 & Spherical & 0.3 & 1200 & 26.180 & 45.779 \\
\hline 8 & Spherical & 0.5 & 800 & 33.767 & 47.837 \\
\hline 9 & Spherical & 0.7 & 1000 & 45.925 & 62.528 \\
\hline
\end{tabular}

\subsection{The Influence of Forming Parameters on Residual Stress}

Figures (10) and (11) clarify the influence of tool shape, stepover and feed rate on the residual stresses for $\left(\alpha=45^{\circ}\right)$, while the figures (12) and (13) show the effect of these parameters on the residual stresses for $\left(\alpha=55^{\circ}\right)$. From these figures, it is obviously noted that the raise in step over leading to raise the amount of residual stresses, because of the high energy generated through the pressure that obtained higher stretch. Also, increasing the feed rates leads to raise the residual stresses values because of increasing the friction at the interface between the tool and sheet leads to poor quality for the parts of. On the other hand, using spherical tool shape gives higher residual stresses than utilizing hemi-spherical or flat-end tool shape. 


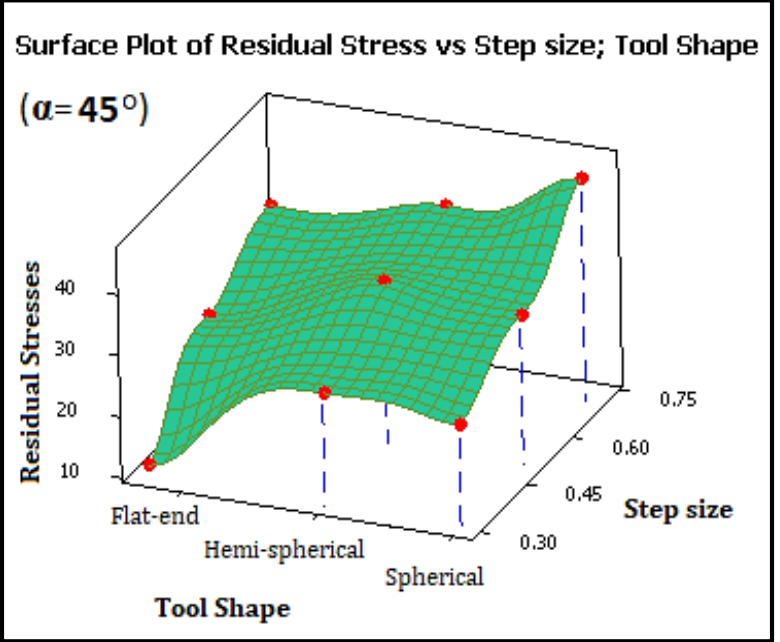

Fig. 10. X- Surface plot of residual stresses vs. Tool shape and step size for $\left(\alpha=45^{\circ}\right)$.

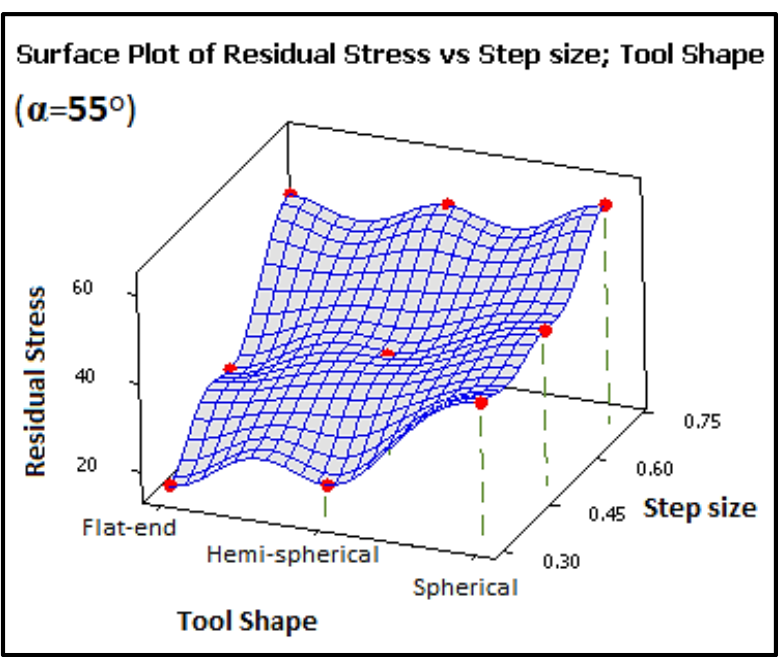

Fig. 12. X- Surface plot of residual stresses vs. Tool shape and step size for $\left(\alpha=55^{\circ}\right)$.

\subsection{Analysis of Variance}

The aim of the analysis of variance (ANOVA) in this work is for determining the significant

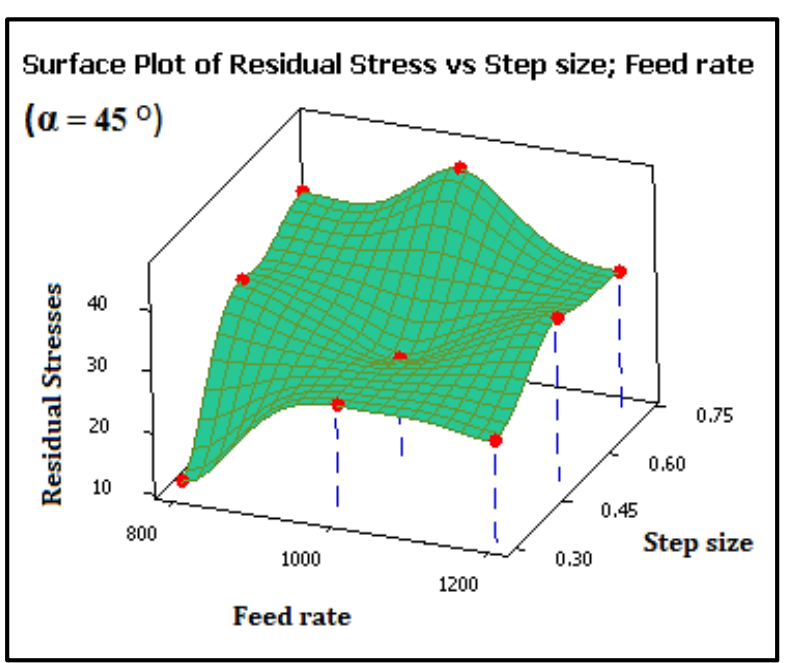

Fig. 11. X- Surface plot of residual stresses vs. Step size and feed rate for $\left(\alpha=45^{\circ}\right)$.

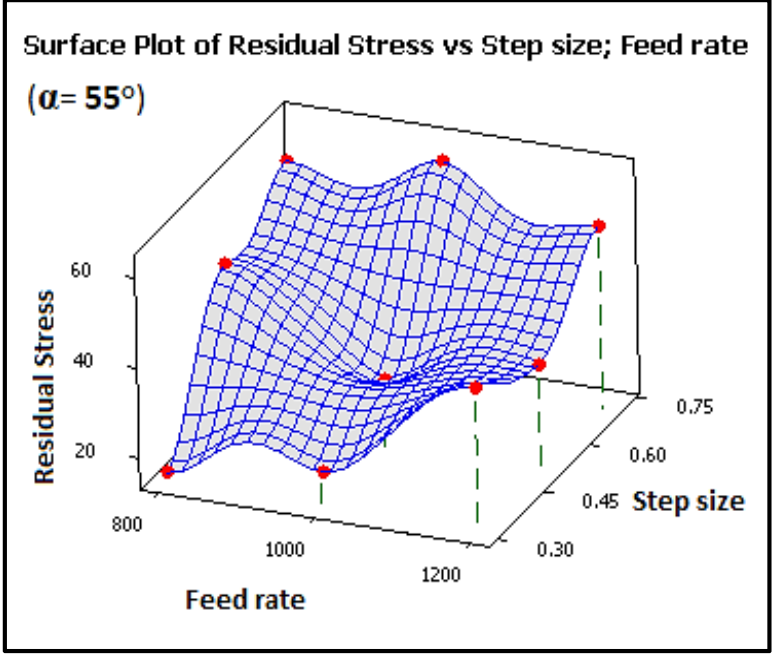

Fig. 13. X-Surface plot of residual stresses vs. Step size and feed rate for $\left(\alpha=55^{\circ}\right)$.

operation variables and for measuring their influences on the residual stress. Table (5) and (6) show the result of ANOVA of factors influencing on the residual stresses.

Table 5,

ANOVA results for Residual stresses $\left(\alpha=45^{\circ}\right)$.

\begin{tabular}{llllll}
\hline Source of variance & DOF & Sum of squares & Variance & F ratio & P(\%) \\
\hline Tool Shape & 2 & 256.9 & 128.5 & 45.09 & 33.90 \\
Step over $(\mathrm{mm})$ & 2 & 448.4 & 224.2 & 78.67 & 59.18 \\
Feed rate $(\mathrm{mm} / \mathrm{min})$ & 2 & 47 & 23.5 & 8.25 & 6.24 \\
Error, e & 2 & 5.7 & 2.85 & & 0.68 \\
Total & 8 & 758 & & & 100 \\
\hline
\end{tabular}


Table 6,

ANOVA results for Residual stresses $\left(\alpha=55^{\circ}\right)$.

\begin{tabular}{llllll}
\hline Source of variance & DOF & Sum of squares & Variance & F ratio & P(\%) \\
\hline Tool Shape & 2 & 602 & 301 & 15.05 & 27.96 \\
Step over $(\mathrm{mm})$ & 2 & 1409 & 704.5 & 35.23 & 65.42 \\
Feed rate $(\mathrm{mm} / \mathrm{min})$ & 2 & 103 & 51.5 & 2.58 & 4.80 \\
Error ,e & 2 & 40 & 20 & & 0.68 \\
Total & 8 & 2154 & & 100 \\
\hline
\end{tabular}

The $\mathrm{F}$ ratio of 78.67 for the step over is greater among the variables (see Table 5). Accordingly, the mostly effected variable at $\left(\alpha=45^{\circ}\right)$ is stepover $(59.18 \%)$ which is about twice of tool shape $(33.90 \%)$. The feed rate has a less influence with $(6.24 \%)$.

On the other hand, the most influential parameter at $\left(\alpha=55^{\circ}\right)$ is also the step over with $F$ ratio value (35.23), and the percentage of contribution is equal to (65.42\%), superior to the first slope angle and it reached to three times of tool shape $(27.96 \%)$ and several times of feed rate, which has the smallest effect on the process with $(4.80 \%)$. Through analyzing, F- ratio is the mean square error ratio to residual, and it is conventionally utilized to compute the importance of factors

\subsection{Optimal Design Conditions for Residual Stresses}

The optimum design conditions have been determined using the main effect plots to obtain the low values of residual stresses. Increasing these kinds of residual stresses (tensile type) raises the availability of cracks and the possibility of failure through. And hence, the better forming parameters were selected using the SPSS software. Figures (14) and (15) show the main effects plot for residual stresses with the process inputs. This plot shows the individual variation response of the three variables, i.e. Stepover, Tool shape and Feed rates separately. The results showed that optimum conditions to the best residual stresses are: Tool shape at level- 1(Flat-end), step over on level$1(0.3 \mathrm{~mm})$, and feed rate on level- $1(800 \mathrm{~mm} / \mathrm{min})$.

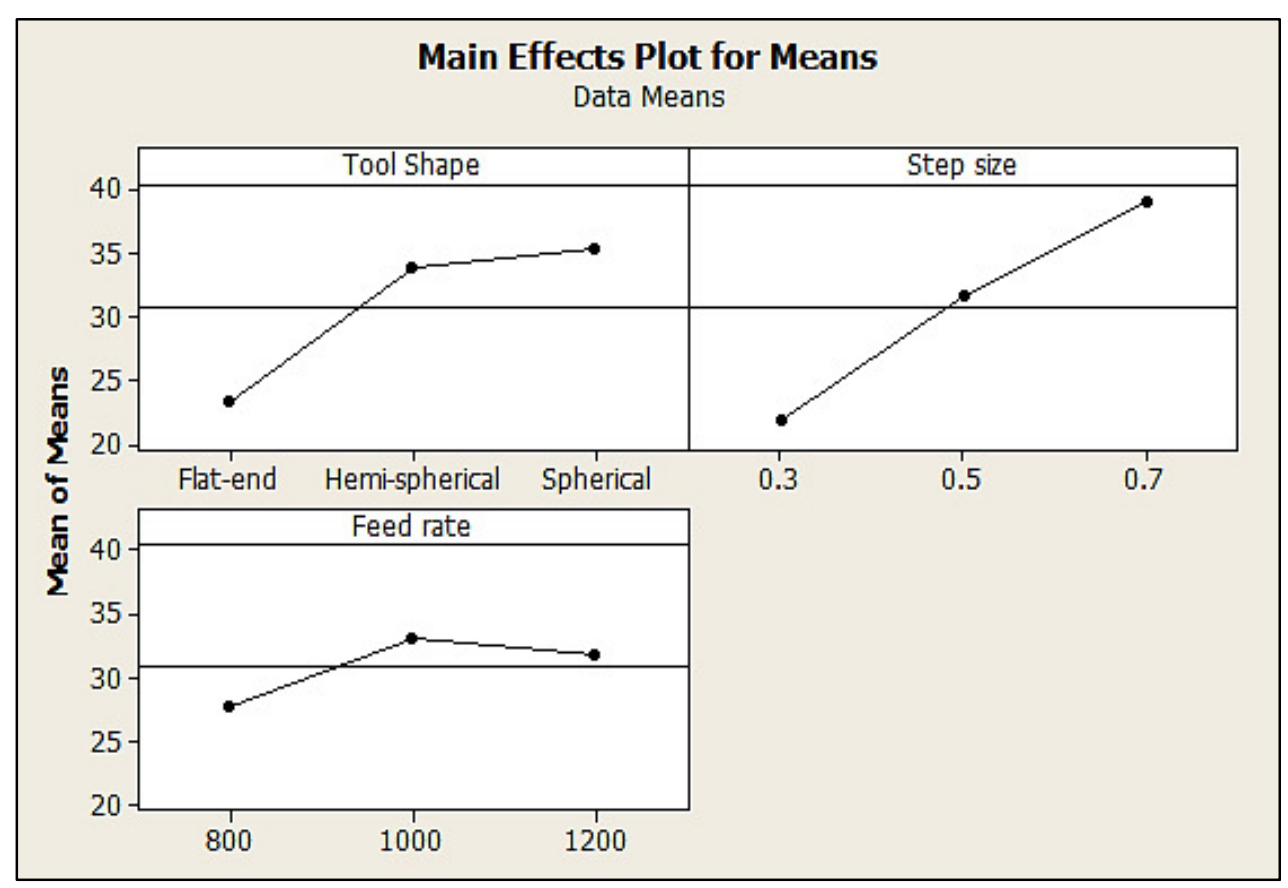

Fig. 14. Mean effects plot for Residual stress at $\left(\alpha=45^{\circ}\right)$. 


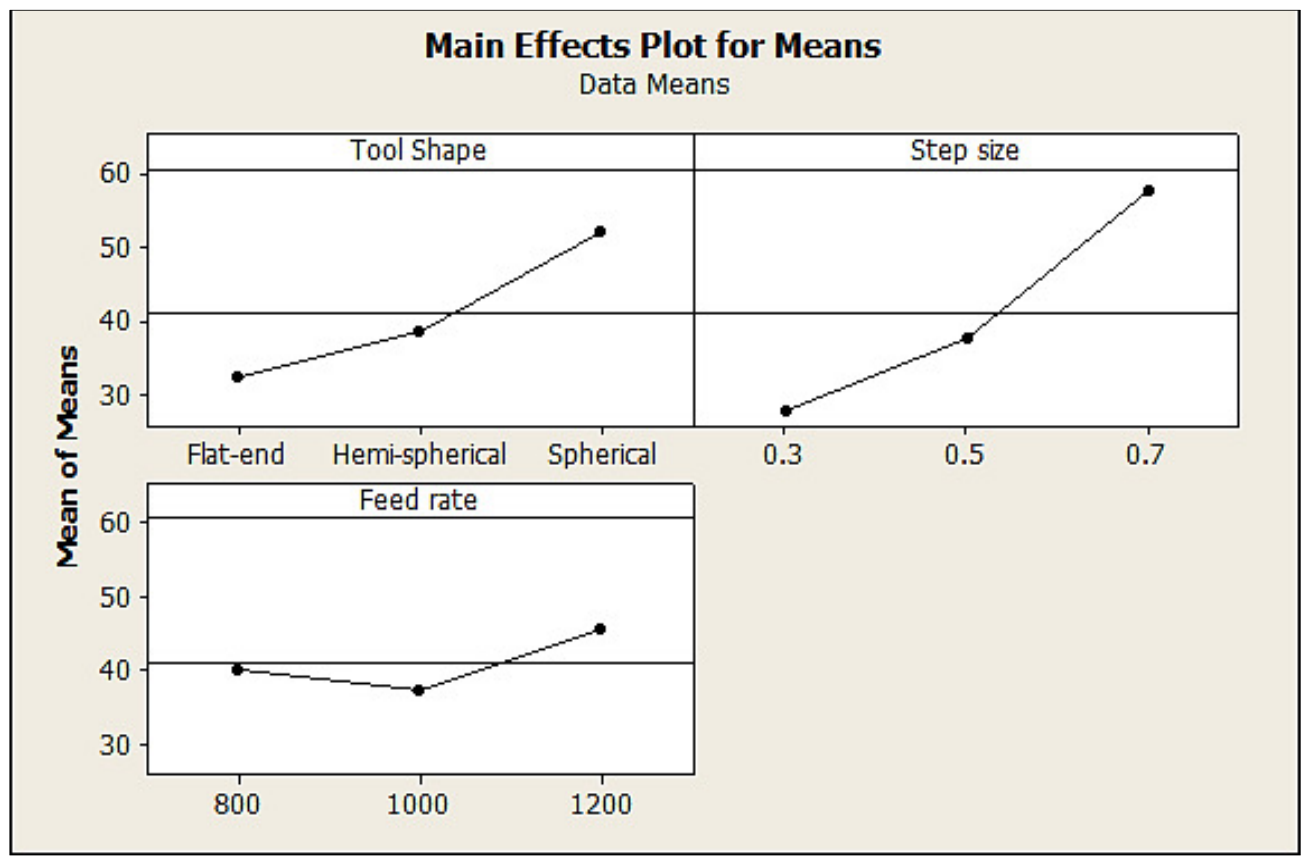

Fig. 15. Mean effects plot for Residual stress at $\left(\alpha=55^{\circ}\right)$.

\section{Conclusions}

To summarize the concluded influences that deduced from these experiments, they could be sum up in:

- The experimental results showed the main effects of process parameters on the residual stresses for Al-alloy. The residual stresses increased with the increasing in step over and feed rates for both slope angles.

- Using spherical tool gives higher residual stresses than utilizing hemi-spherical or toroidal types.

- The optimal conditions for best residual stresses were Tool shape at level-1 (Flat-end), step over at level-1(0.3 mm), and feed rate at level-1(800 $\mathrm{mm} / \mathrm{min}$ ).

- From analysis of variance, the most influential parameter is the step over of $(59.18 \%)$ and $(65.42 \%)$ for both slop angles $\left(\alpha=45^{\circ}\right)$ and $\left(\alpha=55^{\circ}\right)$, respectively which is greater than tool shape and feed rate.

\section{List of Abbreviations}

\begin{tabular}{|c|c|c|}
\hline No. & Symbol & Meaning \\
\hline 1 & ISMF & $\begin{array}{l}\text { Incremental sheet metal } \\
\text { forming }\end{array}$ \\
\hline & SPIF & $\begin{array}{l}\text { Single point incremental } \\
\text { forming }\end{array}$ \\
\hline & $\mathrm{CNC}$ & Computer numerical contro \\
\hline
\end{tabular}

$\begin{array}{lll}4 & \text { XRD } & \text { X-ray diffraction } \\ 5 & \text { OA } & \text { Orthogonal array } \\ 6 & \text { S/N } & \text { Signal to noise ratio } \\ 7 & \Delta Z & \text { Step over } \\ 8 & \mathrm{P}(\%) & \text { Percentage of contribution }\end{array}$

\section{References}

[1]P. Lehtinen, T. Väisänen \& M. Salmi "The effect of local heating by laser irradiation for aluminum, deep drawing steel and copper sheets in incremental sheet forming" Physics Procedia. Vol. 78, pp. 312-319,2015.

[2]K. Jackson \& J. Allwood "The mechanics of incremental sheet forming" Journal of Materials Processing Technology. Vol. 209, pp. 11581174,2009 .

[3]M. Azaouzi \& N. Lebaal "Tool path optimization for single point incremental sheet forming using response surface method" Simulation Modeling Practice and Theory, pp. (49-58),2012.

[4]M. Skjoedt, N. Bay, B. Endelt \& G. Ingarao "Multi Stage Strategies for Single Point Incremental Forming of a Cup" International Journal of Material Forming. Suppl. 1, pp. 1199 $-1202,2008$.

[5]Zemin Fu, Jianhua Mo, Fei Han \& Pan Gong " Tool path correction algorithm for single-point incremental forming of sheet metal" 
International Journal of Advanced Manufacturing Technology. Vol. 64, pp. 12391248, 2013.

[6]S. H. Wu1, Ana Reis, F.M. Andrade Pires, Abel D. Santos \& A. Barata da Rocha " Study of tool trajectory in incremental forming" Advanced Materials Research. Vol. 472-475, pp. 15861591, 2012.

[7]Radu Crina, Herghelegiu Eugen, Tampu Catalin and Cristea Ion "The Residual Stress State Generated by Single Point Incremental Forming of Aluminum Metal Sheets", Journal of Applied Mechanics and Materials Vol.371, pp.148-152, 2013.

[8]Crina Radu, Catalin Tampu, Ion Cristea, and Bogdan Chirita "The Effect of Residual Stresses on the Accuracy of Parts Processed by SPIF", Journal of Materials and Manufacturing Processes, Vol. 28, pp. 572-576,2014.

[9]G. Vigneshwaran, V.S.S. Kumar \& S.P. Shanmuganatan "Optimization of Process Parameters in Single Point Incremental Forming of AA 6063-O Alloy" International Journal of Current Engineering and Scientific Research. Vol. 2, pp. 8-14, 2015.
[10] H. Vemanaboina, D.A. Kumar, B.D. Kumar, K.S. \& L.S. Nayak "Residual Stress Measurement using X-Ray Diffraction for Weldments" IJSRD || National Conference on Recent Trends \& Innovations in Mechanical Engineering, pp 176-179, 2016.

[11] A. Zolanvari, S. H. Sagha, F. Eshaghi, Z. Shahedi \& A. Zendehnam "Microstructure and Residual Stress Measurement of Ag/Glass Thin Films Using In-Situ High-Temperature X-ray Diffraction" Armenian Journal of Physics. Vol. 9, pp. 15-19, 2016.

[12] Shukry H. Aghdeab and Laith A. Mohammed, "Studying Parameters of EDM Based MicroCutting Holes Using ANOVA", Eng. \&Tech. Journal, Vol.31, Part (A), No.15, 2013.

[13] Wissam. K. Hamdan "Feasibility Development of Incremental Sheet Metal Forming Process Based on CNC Milling Machine", $\mathrm{PhD}$. thesis, University of Technology 2009. 


\section{دراسة تأثير متغيرات عملية التثكيل احادية التماس على الاجهادات المتبقية للأسطح الزاوية بالاعتماد على مسار العدة الايزو بلانار الاجلماد}

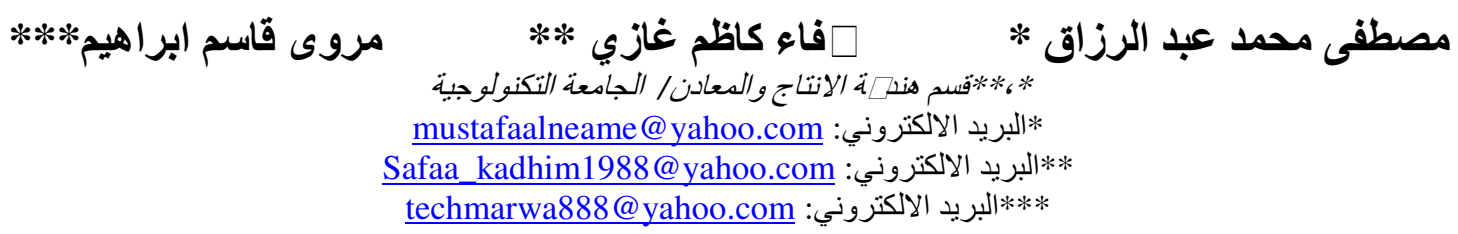

عملية التثكيل التنز ايدية للصفائح (ISMF) هي عملية حديثة في تقنيات تشكيل المعادن، حيث توفر امكانية تصنيع الاجز اء ثلاثية الابعاد المعقدة للصفائح

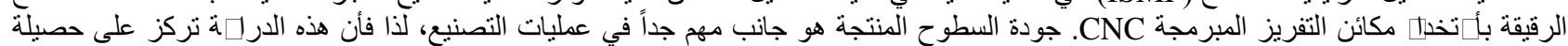

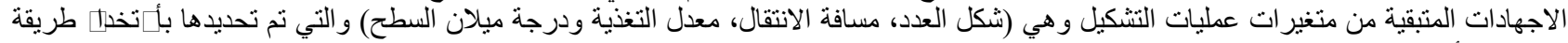

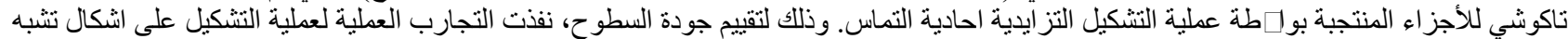

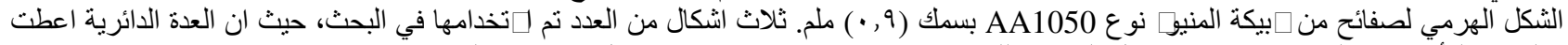

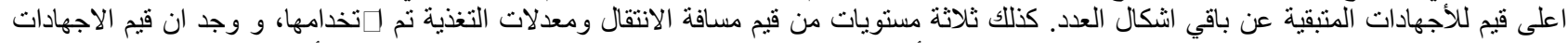

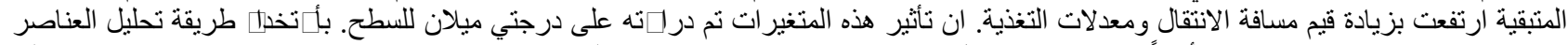

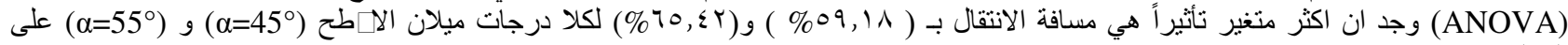

